\title{
RESPONSE OF MARINE CLIMATE TO FUTURE CLIMATE CHANGE: APPLICATION TO COASTAL REGIONS
}

\author{
James Leake ${ }^{1}$, Judith Wolf ${ }^{1}$, Jason Lowe ${ }^{2}$, Jim Hall ${ }^{3}$, Robert Nicholls ${ }^{4}$. \\ Here we present results from wave models of the NE Atlantic and the NW European continental \\ shelf, forced by Met Office Hadley Centre climate model winds, for various future climate scenarios. \\ The wave model (WAM) has been well-validated previously and here it is shown to be statistically \\ in reasonable agreement with the ERA-40 reanalysis for present-day climate. Seasonal mean and \\ extreme waves are generally expected to increase to the SW of UK, reduce to the north of the UK \\ and experience little change in the southern North Sea. There are large uncertainties especially with \\ the projected extreme values, so that although an upward trend in wave height is predicted, it may \\ not be statistically significant.
}

\section{INTRODUCTION}

Many global effects of climate change are now widely recognised but there is a need for detailed regional forecasts of these effects to enable coastal managers to plan for likely impacts. Changes in coastal wave climate, as a result of climate change, would have an effect on vulnerable coastal regions, especially in combination with the effects of storm surges and sea level rise (Wolf, 2008). Waves and swell can damage the coastline, including natural and man-made seas defences. It is important to estimate how the wave climate might alter in the future as a result of anthropogenic climate change, and produce scenarios that are consistent with climate change predictions of other quantities.

The coastline of East Anglia in the UK is susceptible to flooding and cliff erosion (see Figure 1). In this area the Tyndall Centre for Climate Change Research's Coastal Simulator (Nicholls et al. 2005; 2008) is designed to provide stakeholders with the ability to predict the future coastline given a choice of both global future climate scenarios and local shore-line management plans. It uses various numerical models to create a library of predictions of future coastline evolution for these choices. Independent models of offshore waves, storm surges and sea level rise are used to provide input to a nearshore model (Stansby et al., 2006) and ultimately to a model of the coastal morphodynamics for north Norfolk (Roche et al. 2008; Hall et al. 2008; Walkden et al. 2005; 2008).

\footnotetext{
${ }^{1}$ Proudman Oceanographic Laboratory, Joseph Proudman Building, 6 Brownlow Street, Liverpool L3 5DA, United Kingdom

${ }^{2}$ Met Office Hadley Centre (Reading Unit), Department of Meteorology The University of Reading, Earley Gate, Reading RG6 6BB, United Kingdom

${ }^{3}$ School of Civil Engineering and Geosciences, Newcastle University, Newcastle NE1 7RU, United Kingdom

${ }^{4}$ School of Civil Engineering and the Environment, University of Southampton, Southampton SO17 1BJ, United Kingdom
} 
A previous paper (Leake et al. 2008) presented earlier results from this study, showing that the North Atlantic wave model results, driven by winds from the Met Office Hadley Centre climate model, agree reasonably well statistically with the ERA40 study (http://www.knmi.nl/waveatlas, Caires et al. 2004). It showed results for the NE Atlantic and projections for mean and maximum wave height for the A2 and B2 future climate scenarios (see Table 1). Here we include some results of sea level and surge projections as well as waves, focussing on the projected changes in offshore waves on the regional scale for the NW European continental shelf, and discuss the uncertainties associated with estimating future trends.

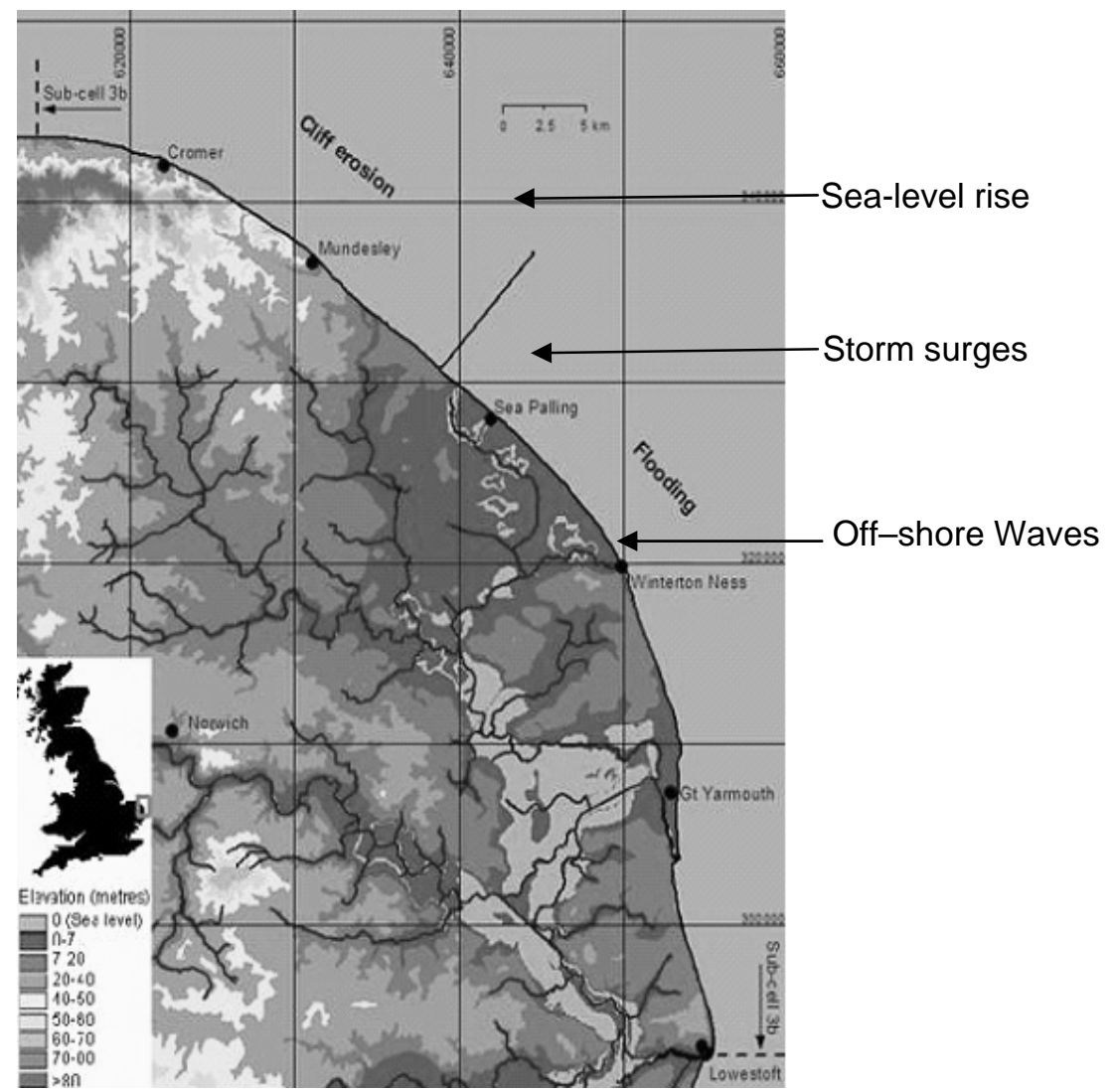

Figure 1. Marine inputs to the Coastal Simulator, north Norfolk, UK 


\section{MODEL HIERARCHY}

For the results presented here the Met Office Hadley Centre OceanAtmosphere Global climate model (OAGCM), HadCM3, was used to project future climate surface winds, which were used to drive a 1-degree wave model of the Atlantic Ocean. This setup allowed wave energy from the South Atlantic to influence the North West European shelf $12 \mathrm{~km}$ wave model (CS3 model). In order to capture synoptic-scale events at mid-latitudes, the coupled climate model provides boundary conditions for $50 \mathrm{~km}$ or $25 \mathrm{~km}$ Regional Climate Models (RCM). Although the RCM is not coupled to the ocean, it is able to run at resolutions which may be adequate to resolve small scale atmospheric events. The ocean boundary conditions in the RCM are provided by SST's from the GCM interpolated onto the RCM grid. The RCM is then used to drive the CS3 wave model domain, using lateral boundary conditions from the Atlantic wave model. Wave model output around the north Norfolk coastline in the southern North Sea is then provided for use in conjunction with tidal, sediment transport and wave transformation model data to investigate long term morphodynamics of the north Norfolk coast, and ultimately to the Coastal Simulator. Model predictions of local sea level and storm surges are also used as input to the coastal model. This methodology could be used in generic applications elsewhere.

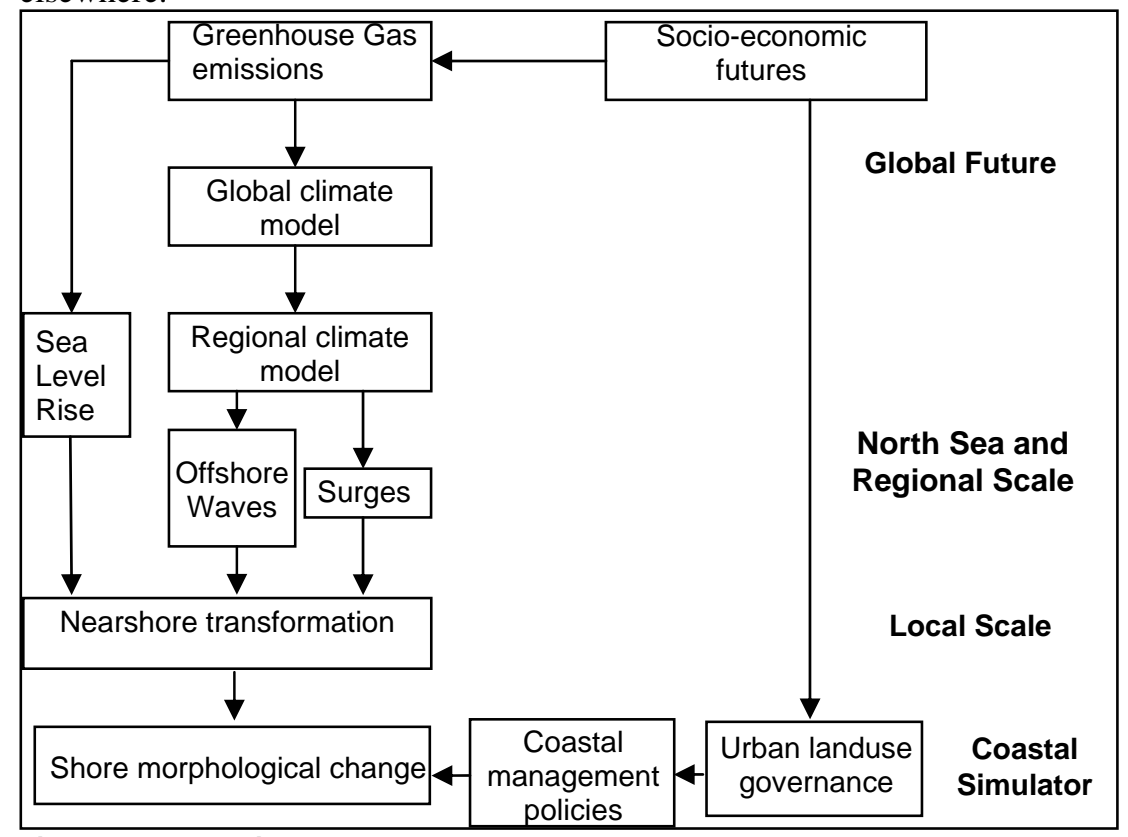

Figure 2. Model hierarchy 
The wave model used here was the $3^{\text {rd }}$-generation spectral WAM model, modified for applications in high resolution shallow water areas, ProWAM (Monbaliu et al., 2000). The model results for the present day were validated statistically against the ERA40 wave model reanalysis (Leake et al. 2008).

\section{Future scenarios}

Global and regional climate models are used to produce both baseline (present day) and future climate scenarios (IPCC 2000). These future scenarios are based on a range of future greenhouse gas emission scenarios, and provide a range of future climates that represent a range of anthropogenic climate change effects (Table 1).

\begin{tabular}{|c|c|c|c|c|}
\hline & Emissions & $\begin{array}{l}\text { Global Temp } \\
\text { increase (C) } \\
\text { (1980-99 to 2090- } \\
\text { 99), best estimate } \\
\text { (likely range) }\end{array}$ & $\begin{array}{l}\mathrm{CO}_{2} \text {-equivalent } \\
\mathrm{GHG} \text { conc. } \\
\text { (ppm by } \\
\text { volume) by } \\
2100\end{array}$ & SLR $(m)$ * \\
\hline$\overline{\mathrm{A} 1 \mathrm{~F} 1}$ & High & $4.0(2.4-6.4)$ & 1550 & $0.26-0.59$ \\
\hline $\bar{A} 2$ & $\begin{array}{l}\text { Medium } \\
\text { High }\end{array}$ & $3.4(2.0-5.4)$ & 1250 & $0.23-0.51$ \\
\hline$\overline{A 1 B}$ & Medium & $2.8(1.7-4.4)$ & 880 & $0.21-0.48$ \\
\hline B2 & $\begin{array}{l}\text { Medium } \\
\text { Low }\end{array}$ & $2.4(1.4-3.8)$ & 800 & $0.20-0.43$ \\
\hline$\overline{\mathrm{A} 1 \mathrm{~T}}$ & & $2.4(1.4-3.8)$ & 700 & $0.20-0.45$ \\
\hline$\overline{B 1}$ & Low & $1.8(1.1-2.9)$ & 600 & $0.18-0.38$ \\
\hline
\end{tabular}

\section{* Excluding future rapid dynamical changes in ice flow}

Here we use a range of climate model driving data. Results from the A2 and B2 scenarios from a 50km RCM were used to investigate variability due to different future emissions. Results from A1B (which leads to a global temperature increase intermediate between A2 and B2) were estimated for 3 versions of the $25 \mathrm{~km} \mathrm{RCM}$, to investigate the spread in results due to the differences in climate model parameters. The 3 versions span a range of climate sensitivity. The models were integrated for 2 time periods:

- 1960-1990 baseline GHG forcing

- 2070-2100 with A2 and B2 GHG forcing

- 1960-2100 with A1B GHG forcing

In the $\mathrm{A} 1 \mathrm{~B}$ experiments, the unperturbed climate model was integrated for the whole 140-year period from 1960-2100, which enables more detailed 
examination of the decadal-scale variability. The wave model was run for the two other ensemble members for the two 30-year time-slices as in phase 1.

\section{RESULTS}

Local sea level consists of a mean sea level (MSL) component as well as transient changes due to tides and surges. Mean sea level is projected to rise globally due to climate change (see Table 1) as a result of thermal expansion and melting of land-ice. Results from the latest international consensus were published in the IPCC $4^{\text {th }}$ Assessment Report (IPCC 2007). There are spatial variations on a regional scale in the mean sea level projections of the order of $+10 \mathrm{~cm}$ and the net local sea level change depends on various factors including vertical land movement (VLM). Around the UK the variation due to VLM is of the order of $\pm 15 \mathrm{~cm}$. In order to examine future extreme water levels we need to consider storm surges. Figure 3 shows the projected change in the 50-year return period water level around the UK, for the A2 scenario, due to changes in atmospheric storminess, an increase in mean sea level and vertical land movements (Lowe and Gregory 2005).
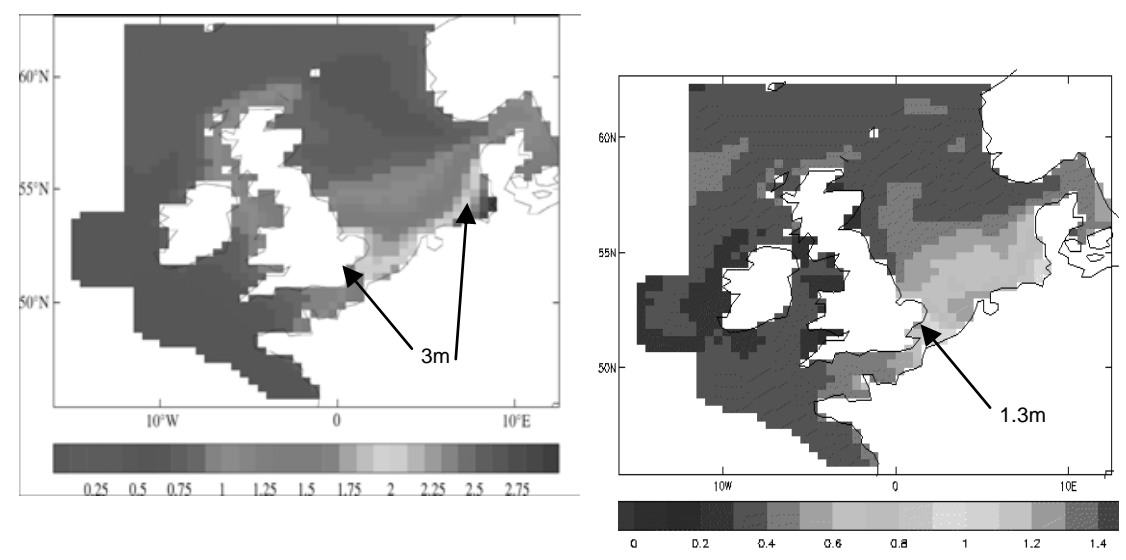

Figure 3. Change in the height $(\mathrm{m})$ of a 50 year return period extreme water level event (present day in left panel, change in right panel), measured relative to the present day tide, due to changes in atmospheric storminess, an increase in mean sea level and vertical land movements. Results are shown for the A2 scenario (from Lowe and Gregory 2005) 

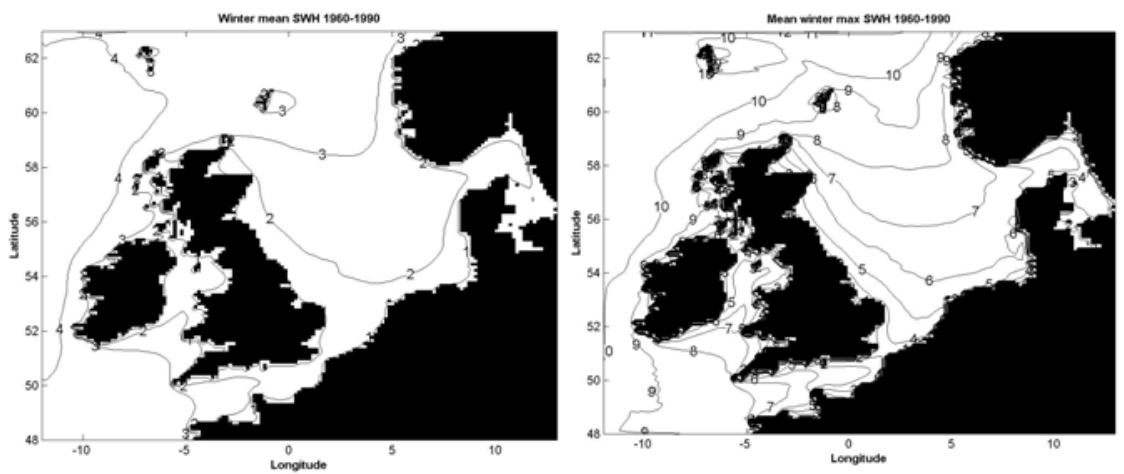

Figure 4. Present-day winter mean and mean annual winter maximum wave height $(\mathrm{m})$

Figure 4 shows the mean and mean winter maximum wave height for the present day. Maximum wave heights are seen to occur to the west of the British Isles, with highest waves in the NW Approaches, to the NW of Scotland. Smaller waves occur in the North Sea and especially the southern North Sea due to its being relatively sheltered from the North Atlantic, with shorter fetch for local wave generation.
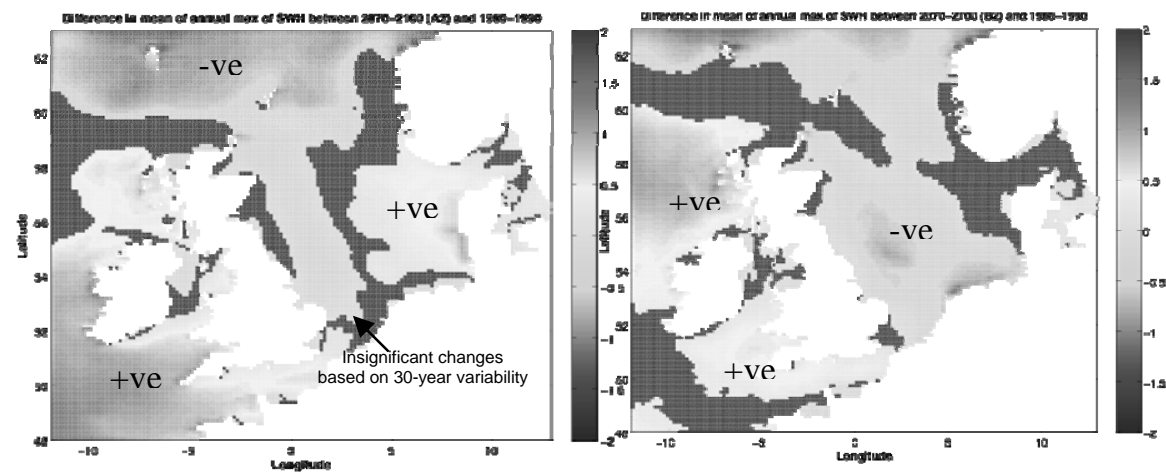

Figure 5. Future changes in mean annual maximum wave height for scenarios A2 (left) and B2 (right). Areas of darker shading are where results are not statistically significant at $5 \%$ level

Figure 5 shows the projected change in the mean and mean annual maximum wave height (effectively this is the same parameter as the winter maximum), for the A2 and B2 scenarios, comparing the two 30-year time-slices (2070-2100 versus 1960-1990). Areas where the changes are not statistically significant (by Student's t-test) have been masked out by darker shading. This 
represents the natural variability within a 30-year period. Largest values are +2 and $-2 \mathrm{~m}$. Increases are projected to the west and SW of the British Isles, with decreases in the central North Sea and to the north. The A2 scenario shows an increase in the eastern part of the North Sea which is not seen in B2 and A2 has the largest increase to the SW whereas B2 has the largest increase to the NW. These changes suggest subtle changes in storm tracks which need to be examined in more detail.

Using the 140-year unperturbed run for the A1B scenario in phase 2 allows us to examine natural variability (within the climate model) over the whole period (Figure 6). In this figure a 30-year running mean has been applied to the wave height for a location in the southern North Sea. It may be seen that there are quasi-periodic variations on quite long multi-decadal time-scales. The amount of variability means that although a long-term upward trend in wave height is modeled, it is not necessarily statistically significant.

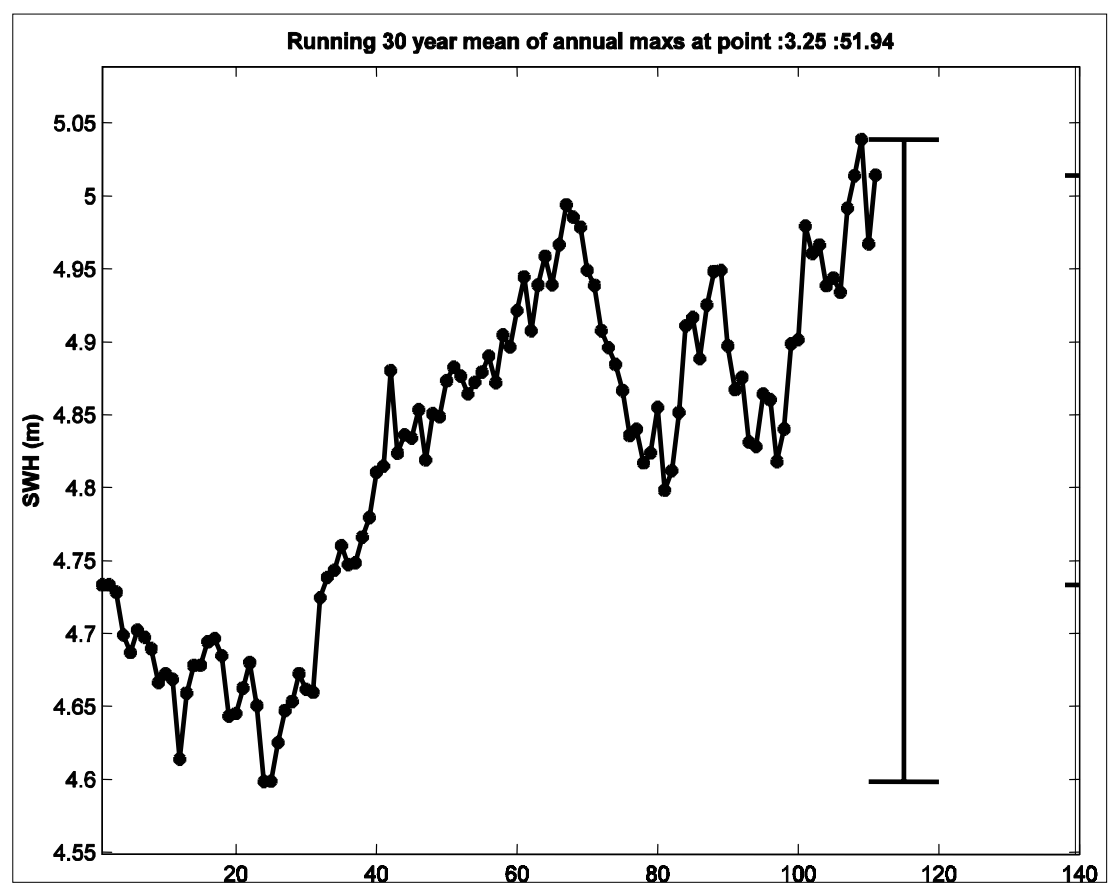

Figure 6. 30-year running mean of annual maximum wave height at a point in the southern North Sea

The changes in the projected wave height in the southern North Sea are generally smaller than other areas and not always statistically significant. Some slight changes in wave direction are projected. The typical distribution is for largest waves from the NE with a secondary peak from the SE. The future 
projection is for slightly fewer waves from the SE and more from the NE in the winter, with a reversal of this pattern in the summer. This may have some implications for the net long-shore sediment transport.

\section{CONCLUSIONS}

We are entering a new generation of marine climate change scenarios i.e. from just having MSL change and speculative scenarios of changes in surge and waves, to transient multivariate time series outputs. This allows us to better quantify uncertainty in our projections of the coastal impact of climate change. The existence of long period (multi-decadal) variability makes the detection of trend problematic.

The GCM-RCM-surge-wave model system is providing the boundary conditions for the Tyndall Centre Regional Coastal Simulator, described in other papers in this volume.

The evidence for storm surge increase in north Norfolk, for the Hadley/POL ensemble, indicates no significant trend across the ensemble members.

Only small changes in extreme wave heights are projected in the southern North Sea. Changes in wave direction may have more significance for coastal processes e.g. longshore sediment transport.

\section{ACKNOWLEDGMENTS}

This work was partly funded by the Tyndall Centre for Climate Change Research.

\section{REFERENCES}

Caires, S., A. Sterl, J.-R. Bidlot, N. Graham, and V. Swail. 2004. Intercomparison of different wind wave reanalyses. Journal of Climate, 17, 1893-1913.

Hall, J., M. Walkden, and J. Thomas. 2008. Probabilistic simulation of longterm shore morphology, North Norfolk, UK. Proceedings of the ICCE 2008 (this volume).

IPCC 2000. Emissions Scenarios: Special report of the Intergovernmental Panel on Climate Change (IPCC) [Nakicenovic, N. and Swart, R. eds.] Cambridge University Press. 598pp.

Leake, J., J. Wolf, J. Lowe, P. Stansby, G. Jacoub, R. Nicholls, M. Mokrech, S. Nicholson-Cole, M. Walkden, A. Watkinson and S. Hanson. 2007. Integrated Modeling for Coastal Impacts. Proceedings 10th International Conference on Estuarine and Coastal Modelling, November 2007, Newport, Rhode Island. ASCE. New York. 
Lowe, J. A., J. M. Gregory and R. A. Flather. 2001. Changes in the occurrence of storm surges around the United Kingdom under a future climate scenario using a dynamic storm surge model driven by Hadley Centre climate models. Journal of Climate, 18(3-4): 179-188.

Lowe, J.A. and J.M. Gregory. 2005. The effects of climate change on storm surges around the United Kingdom. Philosophical Transactions of the Royal Society. Series A, Mathematical and Physical Sciences, 363, 1313-1328. doi:10.1098/rsta.2005.1570

Monbaliu, J, R. Padilla-Hernández, J. Hargreaves, J.C. Carretero, W. Luo, M. Sclavo, H. Gunther. 2000. The spectral wave model, WAM adapted for aplications with high spatial resolution. Coastal Engineering 41, 41-62

Nicholls R.J., M. Mokrech, S.E. Hanson, P. Stansby, N. Chini, M. Walkden, R.Dawson, N. Roche, J.W. Hall, S.A. Nicholson-Cole, A.R. Watkinson, S.R. Jude, J.A. Lowe, J. Leake, J. Wolf, C. Fontaine, M. Rounsvell and L. Acosta-Michlik. 2008a. The Tyndall Centre Coastal Simulator and Interface (CoastS). Proceedings of FloodRisk2008, 30 September - 2 October, Oxford, $U K$

Nicholls, R.J., M. Mokrech, and S.E. Hanson. 2008b. The Tyndall Coastal Simulator and Interface. Proceedings of the ICCE 2008 (this volume).

Roche, N., R. Dawson, J. Hall and M. Walkden. 2008. Projected long term changes in flood risk on the East Anglian coast of the UK: probabilistic analysis of the relationship between climate change, coastal morphology and coastal engineering. Proceedings of the ICCE 2008 (this volume).

Stansby, P.K., J.G. Zhou, C.-P. Kuang, M.J.A. Walkden, J.W. Hall, and M. Dickson. 2006. Long-term prediction of nearshore wave climate with an application to cliff erosion, Proceedings of the 28th International Conference on Coastal Engineering, San Diego, ASCE, New York.

Walkden, M.J.A. and J.W. Hall. 2005. A predictive mesoscale model of the erosion and profile development of soft rock shores. Coastal Engineering. 52, 535-563.

Walkden, M.J., J.W. Hall, R., Dawson, N. Roche, and M. Dickson. 2008. Coastal flood risk analysis driven by climatic and coastal morphological modelling, Proceedings of FloodRisk2008.

Wolf, J. 2008. Coastal Flooding - Impacts of coupled wave-surge-tide models Natural Hazards: in press. 